\title{
8. The Unit of Analysis in IS Theory: The case for activity
}

\author{
Helen Hasan \\ University of Wollongong \\ Sumayya Banna \\ University of Wollongong
}

\begin{abstract}
In the field of information systems (IS), researchers use and adapt existing theories to make sense of their data. They also build new theory from their research findings. The way theory is used, adapted or created usually assumes a certain unit of analysis, which could be the artefact, the system, the organisation, the user, the developer, the team or something else. In this chapter, we propose that 'activity' should also be considered as a suitable unit of analysis for theory in IS since the purpose of any information system is to facilitate the activities for which it is used. To support this proposition, we describe the basic tenets of activity theory and how they can be used to underpin IS research. We illustrate these with the interpretation, through activity theory, of a health information system development that aimed at identifying and meeting the needs of various users' activities. We make the claim for activity as an appropriate unit of analysis when using existing theory in IS research and when building new theory for information systems.
\end{abstract}

\section{Introduction}

In the field of IS, researchers regularly use existing theories from more established disciplines to interpret or make sense of their data. They also adapt or combine these theories to create new theoretical frameworks in order to make them more appropriate to the particular requirements of IS research. In addition, IS researchers build new theories of various types (Gregor, 2006) from their research findings.

The way theory is used, adapted or created usually assumes a certain unit of analysis, which could be the artefact, the system, the organisation, the user, 
the developer, the team or something else. We are not suggesting there is anything wrong with having theories that are built around these different units of analysis. Indeed, we believe that it is appropriate for a multidisciplinary field such as IS to have multiple theories addressing a range of units of analysis. We propose that 'activity' should be considered as one of the suitable units of analysis for theory in IS since the purpose of any information system is to facilitate activities. To explicate this proposition, we draw on the tenets of activity theory - an established and respected theory of human activity that has been around for nearly a century, long before the advent of computers. The foundational work of activity theory was published in Russian and translated into English only many decades later (for example, Leontjev, 1981; Vygotsky, 1978). As with any theory, it has its own concepts and language, with English words (particularly subject, object, action, activity) only approximations of their Russian counterparts.

There has already been a substantial body of work in IS and related fields that makes use of activity theory or adaptations of it. Examples include the work of Bødker (1991b), Engeström (1987), Gould (1998), Kaptelinin (1996), Korpela et al. (2000), Kuutti (1991), Star (1998) and Suratmethakul and Hasan (2004). In the next section, we present the lessons we draw from this body of work on how the tenets of activity theory can be used to underpin IS research. We describe the relevant concepts and the language of activity theory in the third section and then illustrate the use of activity theory in IS with an interpretation of a health information system development that aimed to meet the needs of various users' activities.

Finally, we draw conclusions about how our proposal might inform theory building in information systems. We consider that the activity-theoretical framework proved useful for describing a multifaceted web-based information system, its users' activities and their unmet needs, so we propose that, with activity as the unit of analysis, IS research and practice can be described in a systematic way that holistically represents purpose, dynamic context, mediation by tools and contradictions within and between activities as they interconnect.

\section{Lessons from the Use of Activity Theory in Previous Research}

Activity theory is sometimes referred to as the Russian 'general systems theory'. As is evidenced by the seminal works of Engeström (1987), Leontjev (1981) and Vygotsky (1978), activity theory is holistic, comprehensive and convincing. It has been shown to be suitable for rigorous academic studies in many fields, and IS-related research has shown that it is particularly suitable for studies 
of real-world practice. The word 'activity' is a translation from the Russian word 'deyatelnost' that conveys a coherent system of human 'doing', including physical or external behaviour and internal mental processes that are combined and directed to achieve conscious goals (Bedny and Meister, 1997). According to activity theory, activities are the significant things people (the 'subjects') do and are usually long-term projects. Each activity has a purpose (the 'object') that might be concrete/real (for example, to build a technical artefact) or abstract/ ideal (for example, to set up an information system). The motives of an activity are always considered to be objective, in the sense that the 'object' of an activity incorporates the motives of its 'subject', whether the activity is real or ideal (Christiansen, 1996). Activities can be carried out by an individual or a group of people who might have different motives for being involved and different understandings of what is being done. Activities might equally well be carried out by different sets of 'actions' (for example, you might entertain guests by cooking a meal at home whereas I might take them out).

An activity is the minimum meaningful context for understanding individual actions and, unless the whole activity is the unit of analysis, the analysis is incomplete (Hasan, 1999; Kuutti, 1996). Overall, this principle highlights the importance of studying human activities in context, which is of direct relevance to fields of research dealing with socio-technical systems such as humancomputer interaction (HCI) and information systems. Generally, systems are designed to serve a purpose or to support user activities, so a theoretical framework is required to form the basis by placing the user and the user's activities in context, rather than placing the system itself at the centre of the evaluation process. Kuutti (1996) suggests that activity theory can provide this theoretical framework.

Crawford and Hasan (2006) contend that the main reason for the use of activity theory in IS research is that it provides a well-developed framework for analysing the complex and dynamic settings that typically involve ongoing interactions between human (subject) and technical elements (tools or objects). The theory of activity shows the effects of tools and the environment on human actions, reactions and behaviour in work settings and in users' relations with technology (Kaptelinin, 1996; Kuutti, 1996; Nardi and O'Day, 1999). 'Activity Theory, with its focus on accumulating factors that affect the subjective interpretations, the purpose, and sense making of individual and group actions and operations, provides a useful paradigm for the ways in which human experience, needs and creativity shape the design and effectiveness of emerging technologies' (Crawford and Hasan, 2006, p53).

The information technology (IT) artefacts that support information systems have evolved at a rate that makes their use particularly difficult to study. Activity theory can meet this challenge as activities are not static or rigid entities; 
they are under continuous change and development (Kuutti, 1996). Historical development is not linear or structured in a predictable pattern. It is, rather, irregular and discontinuous (Kuutti, 1996). As each activity develops over time, parts of older activities remain embedded in the development process (Kuutti, 1996). Therefore, in order to understand a current activity, it is important to analyse its historical development. Activities are dynamic and in a continuous state of evolution, with development taking place at all the different levels of an activity (Kuutti, 1996). By analysing the elements, it is possible to gain an insight into this evolutionary development process and situate the activity in its historical context.

An activity is always purposeful even if the subject is not fully aware of that purpose. For example, a manager's motivations for using an executive information system might include the desire to be better informed and to make better decisions, but might also include the desire to increase status or to impress one's competitors, along with a variety of other motives (Hasan, 1998). Whether the object is material (physical) or ideal (mental) has a value in itself because it fulfils some human need (Kaptelinin, 1996). Manipulating and transforming a shared object into an outcome over a period is what motivates the very existence of a purposeful activity (Kuutti, 1996). An object only reveals itself in the process of doing and, hence, the object is continuously under development and revealed in different forms for different participants of an activity (Engeström, 1990).

Information systems projects are notoriously subject to conflicts and contradictions and activity theory anticipates this. Different individuals performing or doing an activity might have different motives for doing so, and the motives for carrying out an activity might change over time (Kaptelinin, 2002). For example, if the object of a system development project is to construct a system to make processing more efficient, the motives for doing so might vary from cost reduction (from a manager's perspective) to improving customer care (from a marketer's perspective). The concept of contradictions is core to activity theory and a key attribute of activity systems (Engeström, 1987, 2001). These can be simple conflicts, problems, historically structured tensions, virtual disturbances, gaps, dilemmas, clashes and breakdowns that provide opportunities for innovations and changes to an activity (Engeström, 2001). The absence of a well-balanced activity system, not in equilibrium because of the presence of the contradictions, can be the driving force for change (Engeström, 2001; Kuutti, 1996). In order to analyse the development of an activity system it is important to identify and resolve contradictions. If the tensions between the elements of an activity system are identified then it becomes possible to reconstruct the system in its concrete diversity and richness, for its future development (Engeström, 1999b). 


\section{An Overview of Activity Theory}

Activity theory is a complex conceptual framework that has evolved historically, and continues to evolve as it is applied in research and in practice. In the 1920s, the Russian Vygotsky undertook a comprehensive study of higher mental functions and human consciousness that laid down the foundation of what is called the cultural-historical activity tradition. Vygotsky (1978) believed that the higher psychological function in humans, which is consciousness, differs from the preconscious psyche of animals and is constructed through the communication and interrelationship between subjects (people) and the objective world. Moreover, Vygotsky (1978) proposed that consciousness is not constructed through direct interactions with the world, but that the relationship between humans and objects of the environment is mediated through the use of tools (artefacts) or, in other words, that the direct association between stimulus (S) and response (R) is mediated by tools. This idea was crystallised in Vygotsky's triangular model of a 'complex mediated act' (Vygotsky, 1978), which depicts the relationship between subject, object and mediated artefact as shown in Figure 8.1.

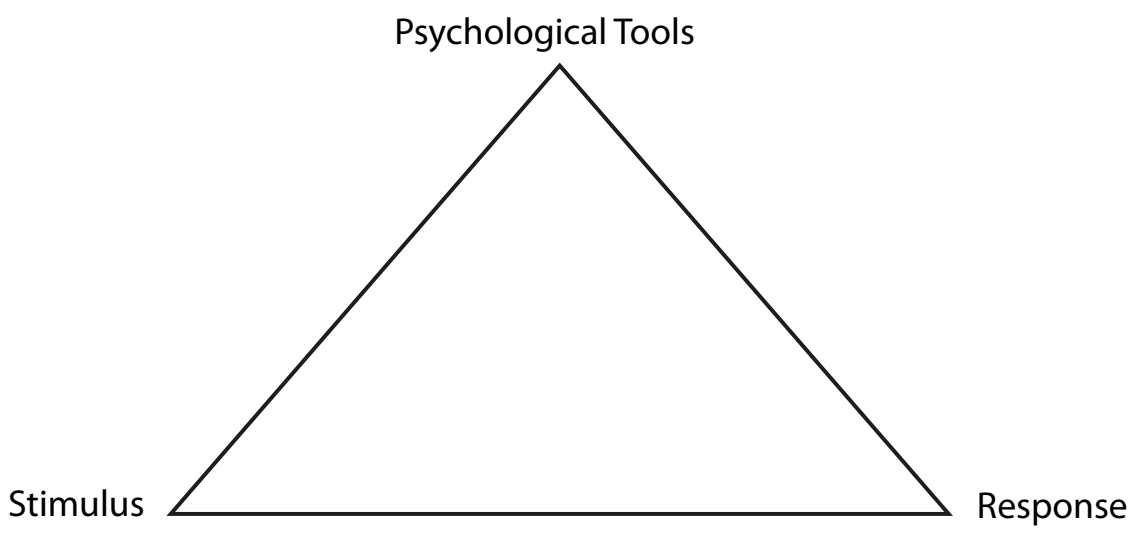

\section{Figure 8.1 The Vygotskian Triad of Mediated Action}

In activity theory, the basic unit of analysis of all human endeavours is activity, which is a broader concept than individual goal-oriented actions (Hasan, 1999). While the initial notion of an activity was generally a physical one, a later notion includes mental activities and incorporates Vygotsky's idea of mental tools as mediators, rather than being limited to only material tools of work. An activity is directed towards an object and defined by it and thus, activities are distinguished according to their object. An activity is then seen as a system in which the structure of activity is not a reaction in itself but a 'system of interrelationships' between people that is mediated by the use of instruments 
and tools (Verenikina and Gould, 1998). This indicates that all human activity is purposeful, is carried out through the use of 'tools' and is socially mediated. What forms the central core of an activity is the dialectic relationship between the subjects (human) and objects (purpose). After Vygotsky's untimely death in the 1930s, his colleagues, Leontjev, Luria and others, began studying human consciousness using the activity approach (Cole, 1996), and these psychologists had a profound effect on the way the theory developed. The essential principles of activity theory now include activity as the basic unit of analysis, object orientation, tool mediation, history and development, the dual concept of internalisation/externalisation, the zone of proximal development and contradictions and conflicts (Engeström, 2005; Kuutti, 1996). Most importantly, it was Leontjev who developed Vygotsky's work into a coherent, integral and conceptual framework for a complete theory of human activity (Leontjev, 1981).

Leontjev's three-level model of activity places 'activity' at the top of the hierarchy shown in Figure 8.2. An activity does not exist without a longterm purpose and strong motives whereas actions are always directed towards specific short-term goals. Participating in an activity involves performing sets of actions and operations. There might be different legitimate sets of actions and operations that will enable subjects to fulfil the purpose of the activity. An action is a conscious representation of progress towards a desired outcome, which consists of an intentional characteristic (what must be done) as well as an operational characteristic (how it can be done). According to Leontjev (1981), an operation is something that is performed routinely in order to complete an action in the current situation and condition. Operations might be performed subconsciously or automated in technology.

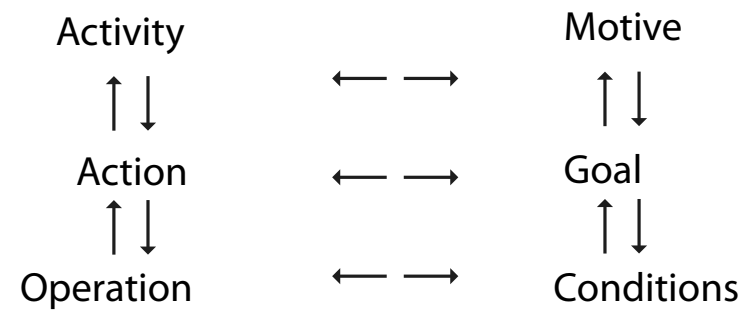

\section{Figure 8.2 Leontjev's Three-Level Model of Activity}

Engeström (1987, 1999a) proposed an enhanced model of the Vygotskian triangle, with additional elements as shown in Figure 8.3, to enable an examination of systems of activity at the macro-level of the community. This expansion of the Vygotskian triangle represents the social or collective elements in an activity system as being community, rules and division of labour. Community consists of all subjects involved in doing the same work or who work collectively. Rules mediate the relationship between subject and community and cover the 
conventions, regulations and social relations within the community that guide the activities and the behaviours in the system. In addition, the relationship between the community and the objects is mediated by the division of labour. This representation of activity also distinguishes between its object or purpose and its outcomes, which may be intended or unintended. In our analysis, we use this popular representation of activity.

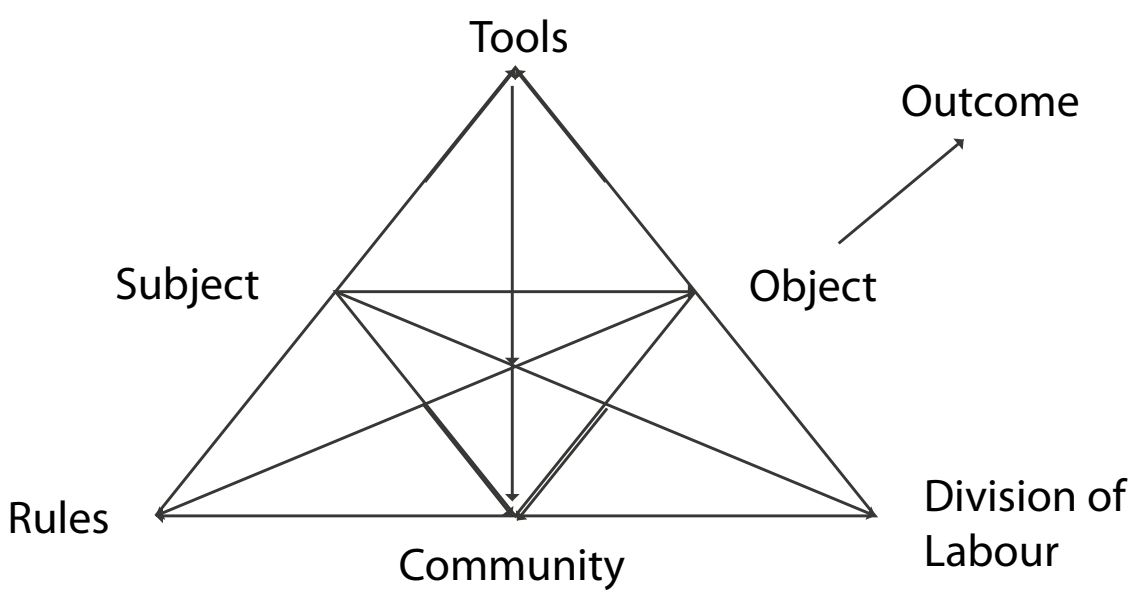

Figure 8.3 Engeström's Structure of Collective Human Activity

Source: Engeström (1999a).

Engeström (1999a) incorporates both internal and external tools in his model of activity as a system, in which internal tools would be the absorption of the inherited culture by learning and training and external tools are the new creations and inventions. An activity can have an individual as subject or can be an engagement of a collective subject composed of a group of people who would bring different skills and understandings oriented by a certain goal or common object that transforms activity into outcomes.

Cole (1999) identified as a limitation of activity theory its insensitivity towards cultural diversity and proposed that it is no longer sufficient to focus on isolated activities. When he applied the framework internationally, the question of diversity and dialogue between different cultures and traditions became a serious challenge. As a result, current users of activity theory make use of conceptual tools for analysing and transforming networks of interacting activity systems and for understanding the dialogues, multiple voices and multiple perspectives. Figure 8.4 shows one type of interaction between multiple activities - namely, where two activities have parts of their object in common (for example, the 
design and use of IT artefacts as described in the seminal work on participatory design of Bødker, 1991a; and Bødker and Gronboek, 1996), depicted as two interlinked activities.

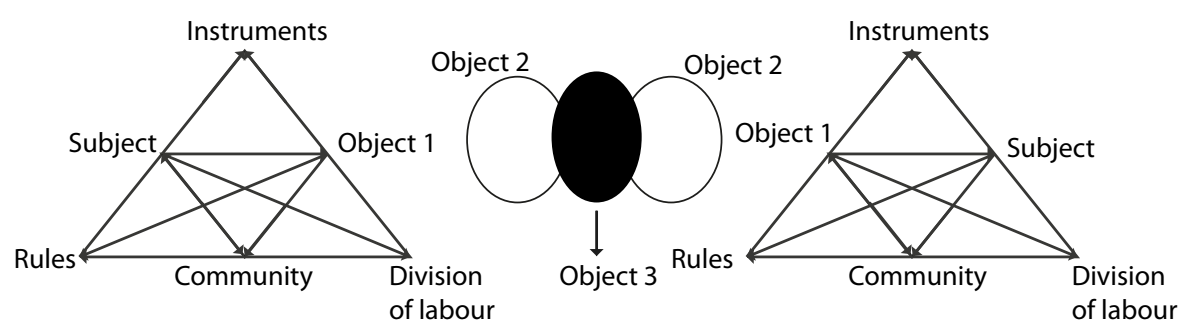

\section{Figure 8.4 Two Interacting Activity Systems as a Minimal Model}

Source: Engeström (1999a, 2001).

Engeström (2001, p. 136) described the object of an activity as 'a moving target, not reducible to conscious short term goals'. This implies that there is a demand for joint and collective work that should be established between different sets of stakeholders, governed by rules and divisions of labour, to determine the new object of interacting activity systems. Following the work of Engeström (1987) and Kuutti and Virkkunnen (1995), an analysis of an activity system normally begins with the identification of one central activity that is the focal point of holistic investigation and is surrounded by other interrelated activities that support the central activity (Hasan, 2003), as shown in Figure 8.5.

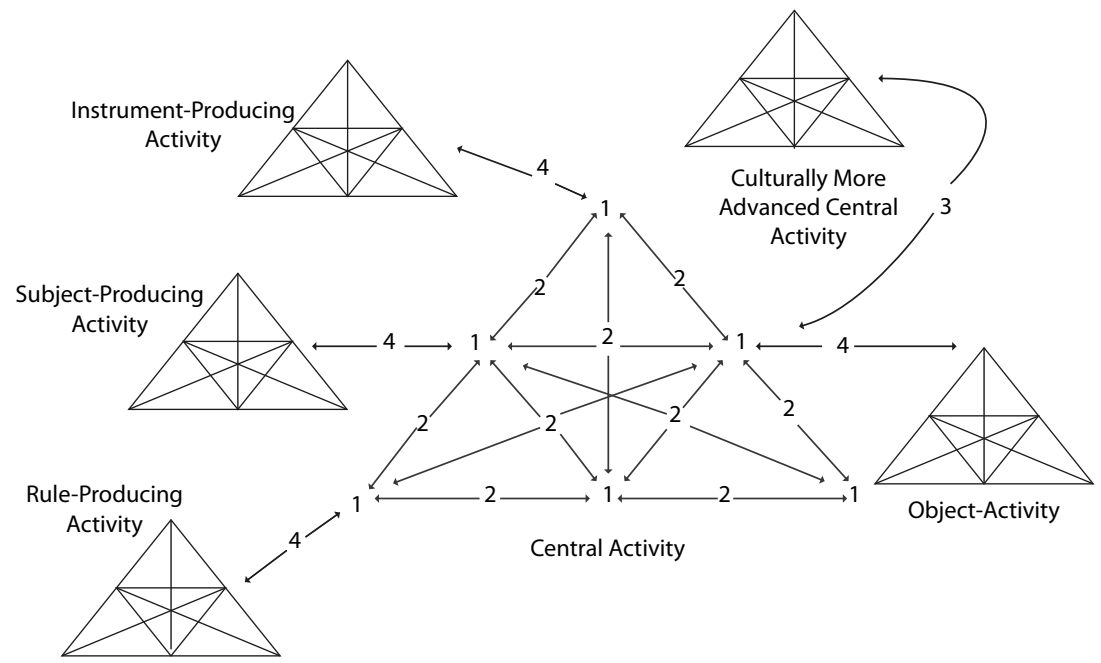

Figure 8.5 A Central Activity and Interconnected Activities 
Engeström (2005) summarised activity theory using five fundamental principles.

- The unit of analysis related to the network of other activity systems is defined in terms of its collectiveness, artefact mediation and object orientation.

- Activity systems are multi-voiced and have a community of multiple perspectives resulting from division of labour amongst the participants.

- The problems of an activity system can be understood through its development and history.

- As tensions accumulate within and between activity systems, contradictions play a central role in the change and development of those activity systems.

- Through a zone of proximal development, activity systems can transform expansively to reconceptualise the object of the activity.

Tool mediation, on which Vygotsky based his original work, is often considered the most fundamental principle of activity theory. It is the use of tools that distinguishes human activity from the activities of animals. Leontjev (1981) asserts that tool mediates activity and thus connects humans not only with the world of objects but also with other people. Because of this humans' activity assimilates the experience of humankind.

An activity is mediated by different types of tools: the tools used and the social context of the work activity. The two-way concept of mediation implies that the capability and availability of tools mediate what can be done and the tool, in turn, evolves to hold the historical knowledge of how a society works and is organised (Hasan, 1999). Human activity is mediated by a number of tools (external and internal). Tools specify modes of operation and are historically developed in social terms, possessing an evolutionary cultural component. An activity is defined by the tool-mediated relationship between subject and object - that is, between the doer and their purpose. Tools expand our potential to manipulate and transform objects, but also restrict what can be done because of the limitations of the tool, which, in turn, often stimulates improvements to the tool. The mediation is a mutual development of both the activity and the kinds of tools used.

There are three kinds of tools that mediate human activity (Bertelsen, 2000; Hasan, 1999; Hasan and Gould, 2001)

- primary tools (artefacts, instruments, machines, computers, and so on)

- secondary tools (language, signs, models, ideas, and so on)

- tertiary tools (cultural systems, scientific fiction, context, virtual realties, and so on).

Since primary tools are physical (material tools), they produce changes to the material object, whereas the secondary tools (psychological tools) influence the 
psyche and behaviour of subjects. Regardless of the type, however, all tools are transmitters of cultural knowledge (Kaptelinin, 1996) or a historical residue of activity development (Kuutti, 1996). Tools determine the modes of operation and are historically developed possessing cultural aspects. As such, the use of these culture-specific tools shapes the way people act (Hasan, 1998; Nardi, 1996). In this sense, this aspect can shape future designs of systems. When the tools are computer based, this notion becomes a source of power (Kaptelinen, 1996), especially when used in the context of analysing the dialectic interactions between people and technologies, and how they are shaped by human activity.

\section{Application of Activity Theory to the Study}

The authors were recently involved in research into the design and implementation of a web-based health information system (hereinafter referred to as the 'Health IS') to support the provision of health information to the medical community and the public. This e-health study will be used here to illustrate the power of activity as a unit of analysis. As mentioned above, activities of design and the use of IT artefacts have been the object of study in HCI and information systems. In this mode of research, the basic activity model is expanded to include a minimum of two interacting activity systems, as shown in Figure 8.4. The design activity is constrained by the computer in various ways, through the actually available materials as well as through the past experiences of designers and users (Bødker et al., 1987). Designers must have primary data about real activities that various users engage in rather than relying solely on their own prior knowledge and experience, and the system functions, to define user tasks. The Health IS can be depicted as the outcome of a 'technical design' activity and a 'tool for the use' activity. The use of participatory design methods where end users are invited to participate in the development of the IS system is currently widespread in the healthcare sector (Pilemalm and Timpka, 2008).

In order to make a better design and ultimately to create better health IT-based artefacts, designers and users undertake a number of interrelated and somewhat overlapping activities that in our case also involved the researchers. The experiences, resources, tools, and so on of designers meet, and sometimes clash, with those of the users, and with others involved. In our concern for the web of activities involving a particular IT-based artefact, the design activities are essential and should emphasise how our understanding needs to reach beyond the immediate use (Bødker, 1991b).

In the course of the project, the researchers created many diagrams to visualise the interconnections between the activities they were observing. An example is depicted in Figure 8.6, which shows the partial overlap between the objects 
of two activities in the manner of Figure 8.4. The bottom triangle is the design activity and the top triangle the use activity of the new Health Information System. A common motive of both activities is to improve healthcare outcomes through shared IS tools. There were, however, some differences in the tools, communities of practice and intended outcomes, with the design activity more concerned with efficiencies and reduced costs through the use of the Health Information System.

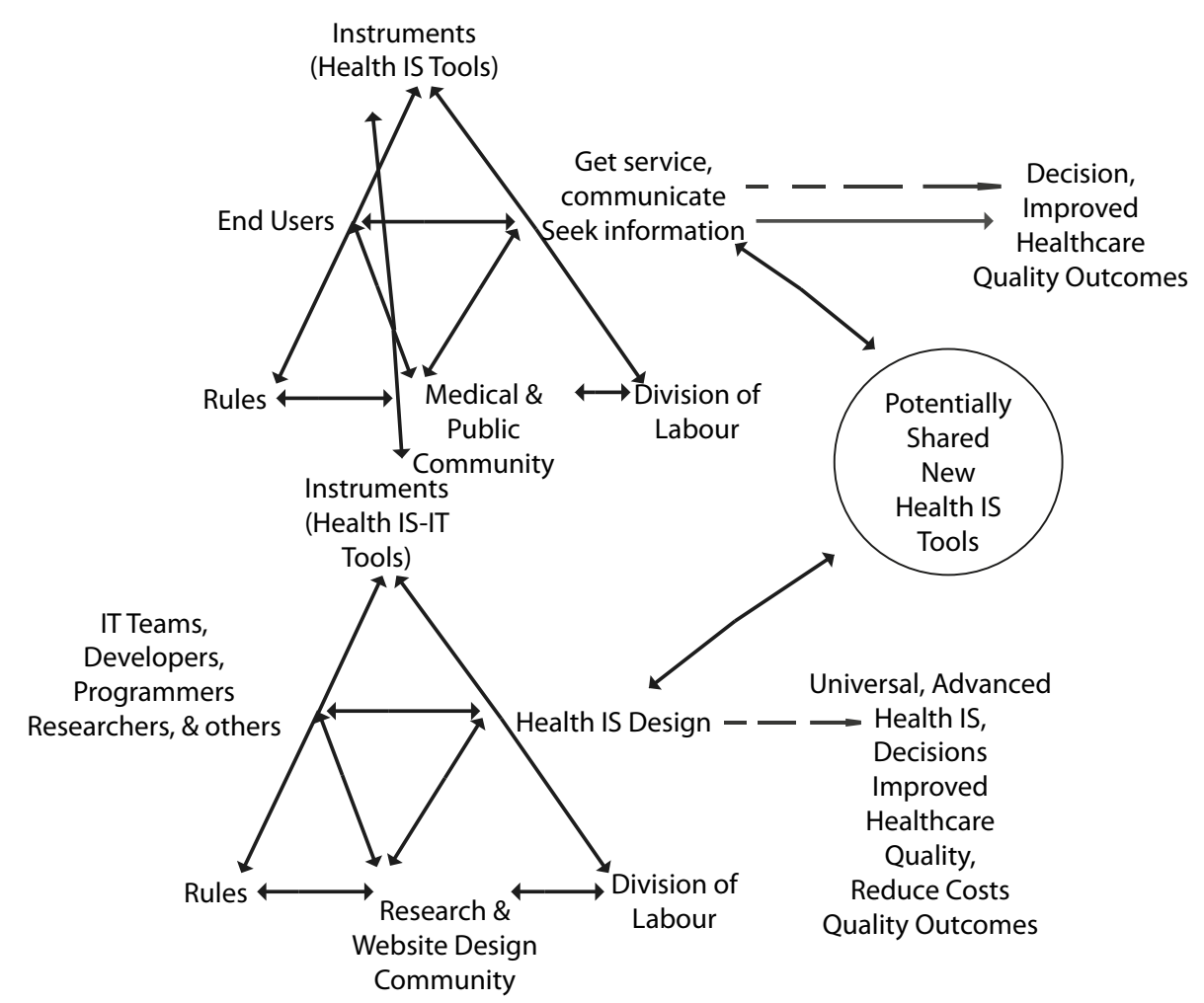

Figure 8.6 One Interpretation of the Interacting Activities of Design and Use

\section{Developing the Research Activity}

We saw our study as depicted in Figure 8.6 but were initially restricted to a study of the use activity only. We therefore began the process of applying the activity theory framework by mapping out 'use' as the central activity and then moving to the surrounding interrelated activities, one of which was the design activity where our findings on the use activity would help the web site designers. 


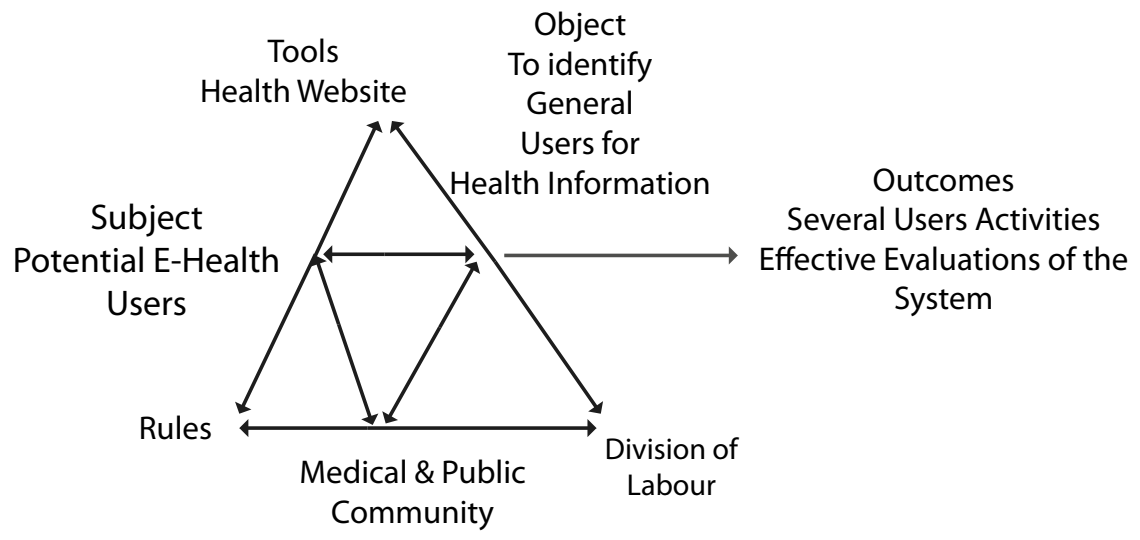

\section{Figure 8.7 The Activity of General Users of Health Information}

Our initial depiction of the activity of end users, for which the Health IS would be a tool, is shown in Figure 8.7 and it was proposed to conduct usability tests on the current web site as a form of action research. Usability testing typically involves carefully producing scenarios to reflect realistic situations in which a person carries out the required tasks using the system being evaluated and tested while the observer or the researcher watches and takes notes. These tests soon revealed that there could be several different activities of use and therefore different activity systems based around these.

The research itself was considered an activity of the research team that was connected to the activities being studied through participatory action research. According to Engeström and Kerosuo (2007), an interventionist researcher must find dialogue partners who share their emotions, concerns and agendas within the activity system. For this reason, we turned to Q Methodology as a discoverymediating tool since it allows the researcher to open up and dig into the subjective views of the participants in a study. It places the participants at the centre of analysis and enables the researcher to explore ways to engage and motivate people. Figure 8.8 depicts the framework for the research activity as used for this study.

A detailed description of this research and the results of the $\mathrm{Q}$ analysis have been published elsewhere (Banna et al., 2010). It is sufficient for our purpose here to report that a three-factor solution was considered the best candidate for interpretation of the data. We labelled these factors, in order from most highly to most lowly ranked, as: 1) 'service-oriented users'; 2) 'interactive users'; and 3) 'information seekers'. These factors were then reinterpreted as activities since, to make sense of the results of the Q study, we took each factor as the unit of analysis and reinterpreted them using the concepts and language of activity theory. 


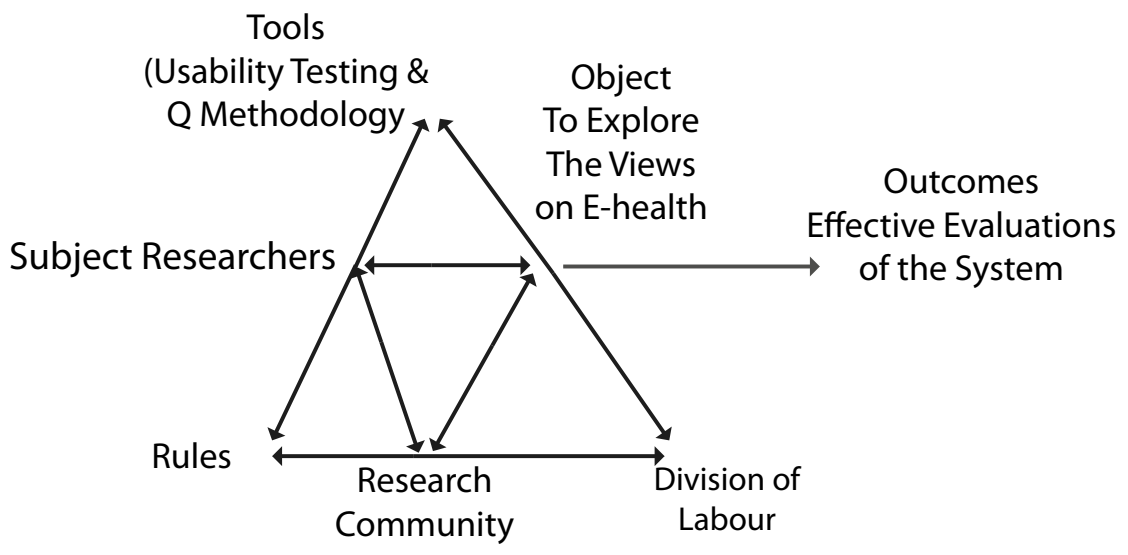

Figure 8.8 The Research Activity

\section{The Activities of the Users}

Drawing on our previous experience with Q methodology, we assumed that each of the three sets of users participates in a different 'use' activity. As subjects of that activity, they have distinct characteristics, have a particular object in mind when they use the Health IS and therefore use a different version of the tool. In other words, the Health IS web site would need to be designed differently in each case. We now describe the activity that each group of users would carry out when they used the Health Information System.

Figure 8.9 shows the 'service-oriented users' in an activity that is bound to the object of getting health services-related information. Those who were located on this factor in the Q study were mainly tertiary students with different majors and degrees (many doing medicine) and medical staff. As the subjects of this activity, they are intelligent and knowledgeable in medical and health service matters. Obtaining specific health-related services information for themselves or others is the object that defines the activity. Making better healthcare decisions is the most common outcome of this activity. Their activity is mediated by the community, which includes well-educated people internal and external to the healthcare system, but knowledgeable of it.

The activity of the 'interactive users' is shown in Figure 8.10. These subjects are not passive recipients but active participants. Their active use of the Internet focuses on a desire to engage in communication. They wanted to use the Health IS to interact with experts, to mutually determine what might be best for themselves as well as others, to engage in collective decision making with regard to tasks and to access information and resources. The outcomes of this interactive activity should allow users to create, share and manage knowledge, skill sets and attitudes needed to cope with the dynamic nature of healthcare settings 
and circumstances. These people included local and international academics, healthcare workers, palliative care staff and the general public, although it is interesting to note that healthcare workers and palliative care staff made up almost 50 per cent of this group. It seems that healthcare workers naturally want to work in teams.

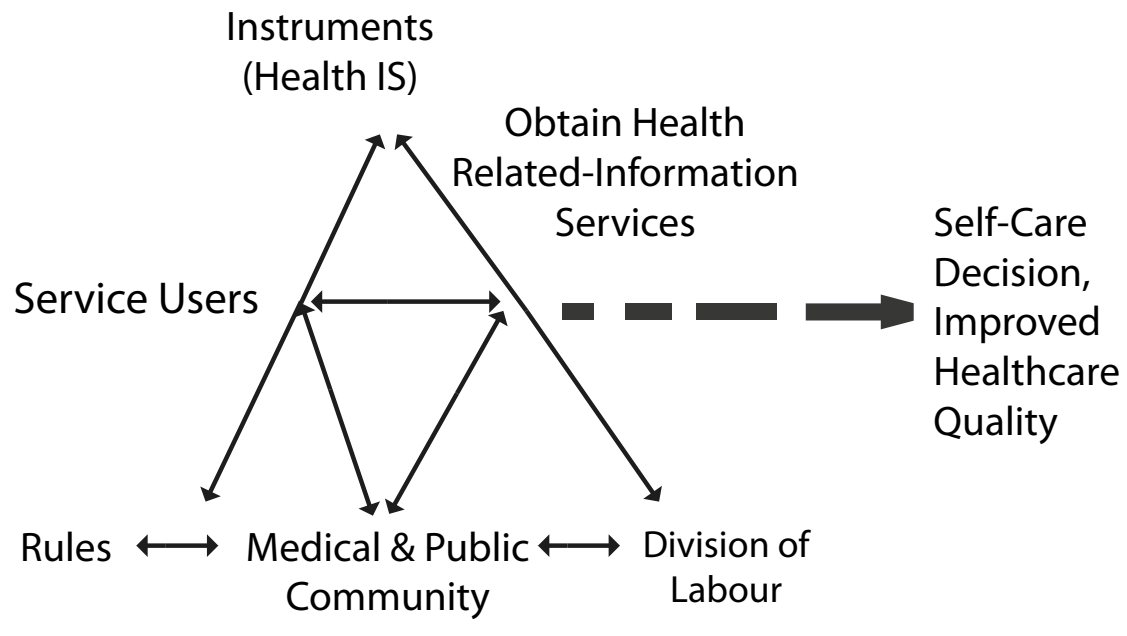

Figure 8.9 The Activity of Getting Information Related to Health Services

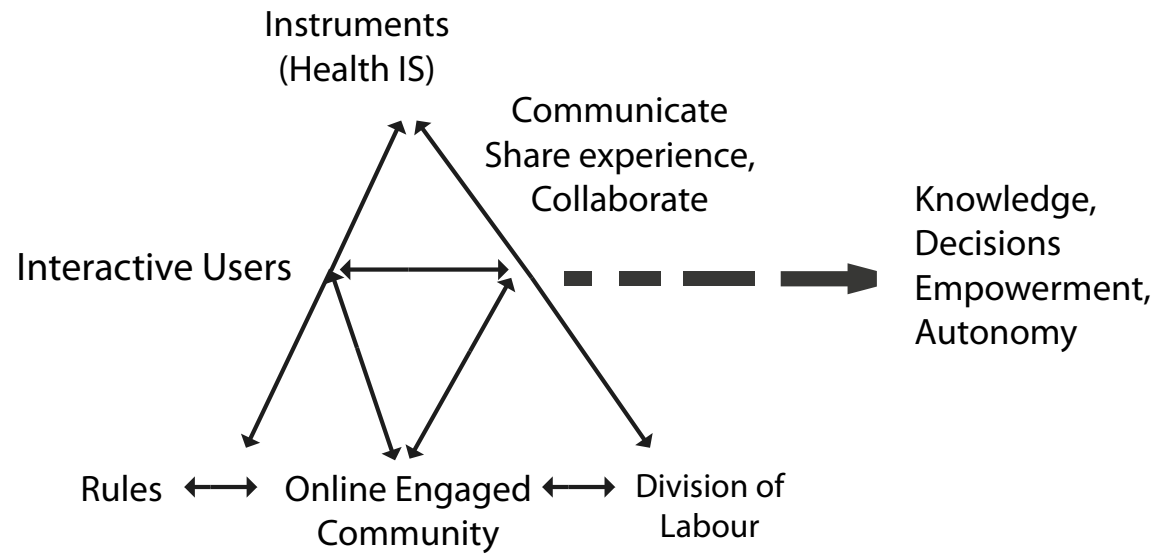

Figure 8.10 The Interactive Communication Activity

Figure 8.11 illustrates the activity of the 'information seekers'. Their core activity is to explore the Internet by themselves to find information. They see health web sites as information-intensive portals that should target a variety of users and enable them to make better health choices and decisions on their own. The subjects of this activity were mainly local and international students and a mix of university staff members. 


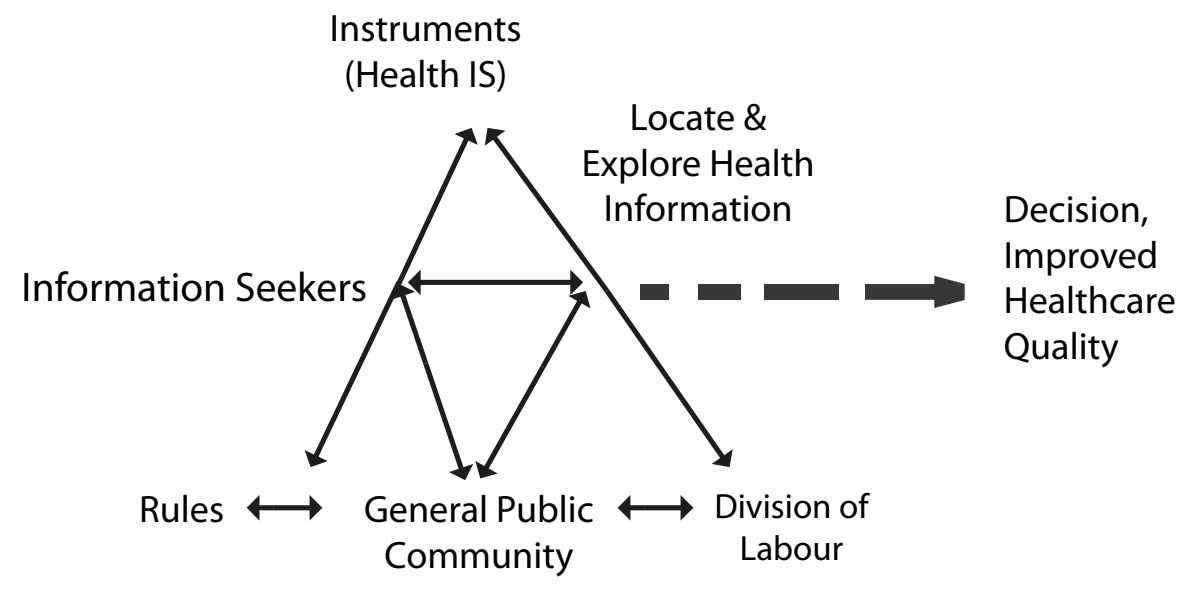

\section{Figure 8.11 The Activity of Seeking Health Information}

Once we had reinterpreted the Q study factors as activities, we could then apply other concepts of activity theory to gain a deeper understanding of the phenomena under investigation. This process is illustrated in the next section of the chapter.

\section{Application of Activity Theory Principles}

\section{Identifying the Mediating Tools for the Activities}

The way tools mediate activities is a key activity theory principle and one particularly significant in IS research and practice. There needs to be consideration of the primary, secondary and tertiary tools that mediate the various activities that are carried out, in this case by the diverse users of the Health Information System. As explained earlier, primary tools are physical and tangible whereas secondary and tertiary tools are psychological and cultural, reflecting and influencing the behaviours of the subjects (Hasan and Gould, 2001). While a web site has obvious physical characteristics - namely, the content and the way it is structured - it is also a secondary tool for the user. The information, knowledge and sense-making it provides should be viewed as tertiary tools. The quality of the physical tool can determine the quality of psychological tools, which are necessary for generating social interaction through a rich representation of information and making communication more effective among healthcare workers on the one hand and between health experts and the public on the other.

Primary tools. A web site acts as a location of primary tools for all user activities: seeking health information, interaction, communication and the exchange of information, and enables users to obtain health-related services. The primary 
tools of interest for information seekers are general search engines. The primary tools among service-oriented users are also search engines and perhaps other more specific navigation tools. In contrast, interactive users are more likely to use social technologies such as email, discussion forums, chat rooms, weblogs and online community services. The term 'Web 2.0' reflects the ongoing transition of the World Wide Web from a simple collection of web sites to a fully fledged computing platform serving these social web applications to end users. Their low cost and connectivity functionality are the lures of these social technologies. They also support new forms of informal network interaction and activity between people, enabling and enhancing informal access to ways of creating and disseminating information.

Secondary tools. These include medical and health knowledge, communication skills, previous or past experiences and specialised language, which might be different for each group of subjects. Healthcare staff use their own medical and professional language, while general users use common non-medical language. Public health web sites also have to consider the multicultural identities and backgrounds of users and so provide information in different languages. Language issues and ways of presenting information can make the design activity more difficult as developers of the system need to design for all levels of language skills. Information brokers might be needed to help in the design. For interactive users, the web site can incorporate new social technologies that enable ordinary people to have a global presence, giving users a new flexibility and independence to support collective actions, knowledge sharing and decision making by self-directed groups.

Tertiary tools. These include, most importantly, the social context. In healthrelated matters, the context is often stressed as users wanting to find and communicate health information concerning their own medical condition or that of a loved one. Stress reduces cognitive capacity and this must be considered in designing the web site, particularly for the service-oriented users. As noted above, healthcare providers constitute more than 50 per cent of the interactive user group. It might be important for healthcare providers to create virtual communities to disseminate the required health information and circulate their ideas and knowledge among themselves. This could result in better decision making and knowledge management that in turn improves healthcare outcomes.

Different activities and different types of tools soon make an activity system diagram quite complicated. For example, if we revisit the simple design-use activity system of Figure 8.6, we might start to add other activities as shown in Figure 8.12. Here the Health IS is depicted as the outcome of both a technical health IS design activity, which considers it as a primary tool, and the data collection activity performed by the information brokers, which considers the web site as a secondary tool. A link between the objects of the Health IS design 
and data collection activities represents the communication and cooperation that is needed if the Health IS is to be both technically sound and provide the right kind of information. In Figure 8.12 a feedback loop has been added from outcomes of the use activity to the link between the design activity and the data collection activity. This feedback loop is particularly important to ensure that the goals of multiple voices or multiple perspectives are met.

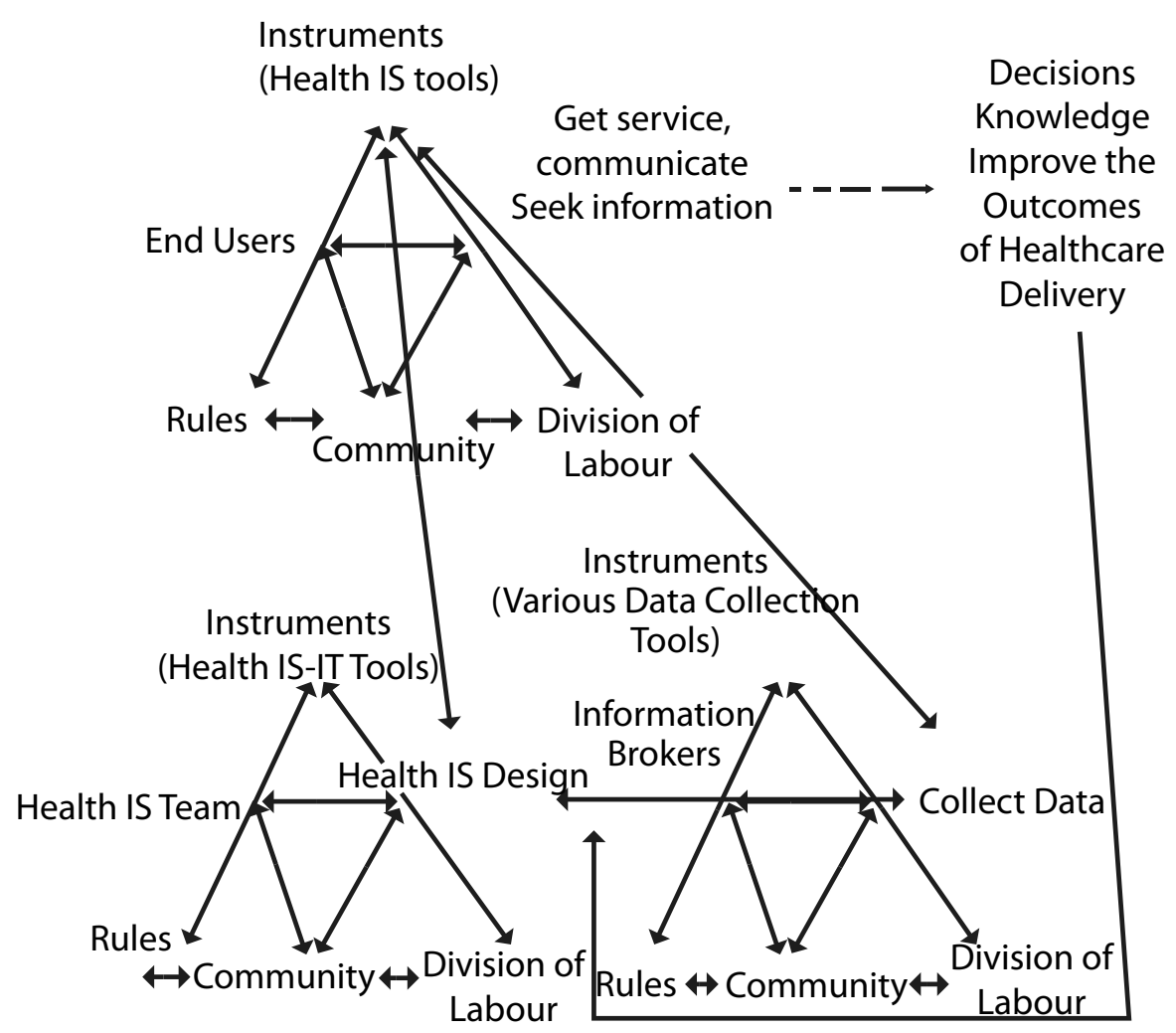

Figure 8.12 The Interrelated Activities of Data Collection, the Use and the Model

\section{Internalisation and Externalisation}

Activities have a dual nature because they have an internal and an external side (Kuutti, 1996). When external mediating tools, such as health web sites, are integrated into functional organ and goal-oriented configurations, they are perceived as an attribute of the individual, implying that they naturally extend the individual's abilities, thus shaping the boundary between internal tool (based inside the human mind) and external tool (the outer world). It is this that distinguishes between expert users and novice users of the Health Information System. The merging of internal and external tools is evident in expert users who use the Health IS as a seamless extension of their abilities. 
In novice users, who are still learning how to use the Health IS, the boundary between the internal and the external tools is the most apparent. The boundary between the internal (human mind) and the external worlds becomes less clear and distinguished when users repetitively use tools to carry out an activity. In other words, expert users are deemed to have internalised more of the central activity as well as the Health IS itself. Users of the Health IS make decisions based on information from external sources, including primary care providers, health web sites, and so on, all of which is internalised and manipulated in the subject's internal plan of action using mental models or maps. This is a dynamic situation and an understanding of this can shape the future design of the system. It creates a challenge for developers to design a system to meet the facts of multiple voices and multi-perspectives of users (novice and expert). Designers rarely consider how the tools they design will mediate activities, and change work practices and social and cultural norms (Hasan, 1999). Mediating tools modify and transform the learner's thinking processes as they begin to use new tools to express their thinking (Cole and Wertsch, 2001). When there is internalisation of an external activity and mastery of the existing Health IS, users tend to develop a need for new mediating Health IS tools. This is so because an activity system is unstable and dynamic, making the design activity an ongoing process.

\section{The Principles of Contradiction and Conflict}

In activity theory, contradiction and conflict are seen as the sources of learning and development. Because of the dynamic nature of activity systems, the Health IS must be designed for change. Therefore, the development of Health IS projects must include processes for user participation and feedback and implementation of new requirements. Within an activity system, there are different people with different backgrounds, motives and perspectives. The notion of multiple voices, described earlier, can be a source of conflict in the design activity but it can also lead to positive action if there is a forum for voicing different user views. It is important to expose multiple voices to negotiation and change when understanding and improving an activity system.

Despite the potential for contradictions to change and transform the activity system, this transformation does not always happen. In fact, contradictions can either enable change or disable change. This depends on whether they are identified, acknowledged and resolved. Hidden, invisible or un-discussable contradictions are the most difficult to identify and these tend to be taken for granted among design teams. From this perspective, to enable innovations, the resolution of contradictions cannot happen at the individual level; it requires social interactions. Human-computer interaction researchers such as Bødker (1991b) have recognised that there has to be close collaboration and cooperation between the use activity and the design activity. This implies that these are in a 
continuous cycle of change where computer applications as well as other parts of work activities are constantly reconstructed using different design tools. A clear knowledge of the changes paves the way to better design.

When analysing tensions, Engeström(1987) proposed four levels of contradiction. Level-one contradictions are breakdowns within and between the elements of action that make up the activity and are affected by other related activities. This means that the same action can be executed by different people for different reasons or by the same person conducting two separate activities.

Secondary inner contradictions are those that occur when users of the system encounter a new element of an activity. The process for incorporating the new element into the activity brings conflicts. For example, designers might face difficulties assimilating and coordinating user requirements and new rules of government and the division of labour. Tertiary contradictions occur between the existing form of an activity and what can be described as a more advanced form of the activity. This might occur when the design activity is reconstructed to take account of new motives, new tools, new user skills or new ways of working. Quaternary inner contradictions are tensions between the central activity and related activities like, for instance, instrument-producing, subjectproducing and rule-producing activities linked to the central activity of the system.

Research in the field of IS takes into consideration the dynamic interplay between information and communication technologies, activity and uses, and patterns of human experiences that emerge over time as the dimensions of the whole system of work activity changes (Crawford and Hasan, 2006).

\section{Conclusion}

We have proposed activity as a suitable unit of analysis for theory-based research in IS, where activity is understood in terms of the concepts and language of activity theory. A recent study by the authors has been reinterpreted as a system of activities to illustrate the value of applying an activity-based framework to IS settings. We applied activity theory because of its holistic and contextual emphasis that is appropriate for qualitative and interpretative research exploring how organisations understand and meet the challenges of designing IS artefacts. In particular, activity theory is known as a well-developed framework and a powerful tool for analysing and providing deep and rich understandings of complex and dynamic settings such as occur in the public healthcare context. This approach relies on taking activity as a holistic and complex unit of analysis, offering a unique lens through which to analyse behaviours, processes, tools and outcomes. 
In several of our studies, the combination of activity theory and Q Methodology has proven an appropriate technique for conducting IS research and interpreting results in an integrated holistic way. The factors that come out of the Q study invariably relate to specific activities of the people who hold similar views on a topic. In this case, examining those activities with the rich concepts of activity theory contributed to an overall understanding of users' perceptions and the purposes of their different activities of use of the Health Information System. Indeed, this leads to the more general observation that humans use diverse information systems on a daily basis to achieve their personal and/ or work objectives, with the expectation that these information systems will facilitate the activities in which they are engaged. Therefore, activities represent a basic element of the context in which systems must exist and operate. Indeed, we contend that attempting to understand information systems is pointless without also attempting to understand the activities in which they are involved. Information systems only become meaningful in the context of use and, in order to successfully undertake the design activity, the use activity must be taken into account.

Activity theory can be used in its traditional form or adapted in ways not anticipated by its founders. For example, the triangular representation of an activity originated by Engeström (1999a) is a relatively recent adaptation but has formed the basis of many studies into complex organisational settings. The concept of an activity, however, remains as a dialectic relationship between subject and object (someone doing something) mediated by tools of various kinds. We suggest that activity as a unit of analysis could be the basis of new theory. In general, we note that in using, adapting or building theory consideration should be given to the unit of analysis it assumes.

\section{References}

Banna, S., Hasan, H., \& Meloche, J. (2010). Subjective evaluation of attitudes towards e-health. Proceedings of AIM Conference, Kuala Lumpur, Malaysia.

Bedny, G., \& Meister, D. (1997). The Russian Theory of Activity: Current applications to design and learning. Newark, NJ: Lawrence Erlbaum Associates.

Bertelsen, O. W. (2000). Design artefacts: towards a design-oriented epistemology. Scandinavian Journal of Information Systems, 12, 15-27.

Bødker, S. (1991a). Activity theory as a challenge to system design. In H.E. Nissen, H. K. Klein \& R. Hirscheim (eds), Information System Research: Contemporary approaches and emergent traditions (pp. 551-64). Amsterdam, Netherlands: Elsevier. 
Bødker, S. (1991b). Through the Interface: A human activity approach to user interface design. Hillsdale, NJ: Erlbaum.

Bødker, S., \& Gronboek, J. (1996). Users and designers in mutual activity: an analysis of cooperative activities in systems design. In Y. Engeström \& D. Middleton (eds), Cognition and Communication at Work (pp. 130-58). Cambridge, UK: Cambridge University Press.

Bødker, S., Ehn, P., Kammersgaard, J., Kyng, M., \& Sundblad, Y. (1987). A utopian experience. In G. Bjerknes, P. Ehn \& M. Kyng (eds), Computers and Democracy - A Scandinavian Challenge (pp. 251-78). Aldershot, UK: Avebury.

Christiansen, E. (1996). Tamed by a rose: computers as tools in human activity. In B. Nardi (ed.), Context and Consciousness: Activity and human-computer interaction (pp. 175-98). Cambridge, Mass.: MIT Press.

Cole, M. (1996). Cultural psychology: a once and future discipline. In V. de Keyser (ed.), Work Analysis in French Language Ergonomics: Origin and current research trends. Volume 34 (pp. 653-69, 1991). Cambridge, Mass.: Harvard University Press.

Cole, M. (1999). Cultural psychology: some general principles and a concrete example. In R. Miettinen, Y. Engeström \& R. L. Punamäki (eds), Perspectives on Activity Theory (pp. 87-106). Cambridge, UK: Cambridge University Press.

Cole, M., \& Wertsch, J. V. (2001). Beyond the Individual-Social Antimony in Discussions of Piaget and Vygotsky. Retrieved from < http://webpages.charter. net/schmolzel/vygotsky/colewertsch.html>

Crawford, K., \& Hasan, H. (2006). Demonstrations of the activity theory framework for research in IS. Australasian Journal of Information Systems, 13(2), 49-68.

Engeström, Y. (1987). Learning by Expanding: An activity-theoretical approach to developmental research. Helsinki, Finland: Orienta-Konsultit.

Engeström, Y. (1990). When is a tool? Multiple meanings of artifacts in human activity. In Y. Engeström (ed.), Learning, Working and Imagining: Twelve studies in activity theory (pp. 171-95). Helsinki, Finland: Orienta-Konsultit.

Engeström, Y. (1999a). Expansive visibilization of work: an activity-theoretical perspective. Computer Supported Cooperative Work, 8(1-2), 63-93.

Engeström, Y. (1999b). Innovative learning in work teams: analyzing cycles of knowledge creation in practice. In R. Miettinen, Y. Engeström \& R. L. Punamäki (eds), Perspectives on Activity Theory (pp. 377-404). Cambridge, UK: Cambridge University Press. 
Engeström, Y. (2001). Expansive learning at work: toward an activity theoretical reconceptualization. Journal of Education and Work, 14(1), 133-56.

Engeström, Y. (2005). Developmental work research: expanding activity theory in practice. International Cultural-Historical Human Sciences. Volume 12. Berlin, Germany: Lehmanns Media-LOB.

Engeström, Y., \& Kerosuo, H. (2007). From workplace learning to interorganizational learning and back: the contribution of activity theory. Journal of Workplace Learning, 19(6), 336-42.

Gould, E. (1998). Psychological information systems frameworks: a contrast between cognitive science and activity theory. In H. Hasan, E. Gould \& P. Hyland (eds), Information Systems and Activity Theory: Tools in context (pp. 39-58). Wollongong, NSW: University of Wollongong Press.

Gregor, S. (2006). The nature of theory in information systems. MIS Quarterly, $3(30), 611-42$.

Hasan, H. (1998). Activity theory: a basis for contextual study of information systems in organizations. In H. Hasan, E. Gould \& P. Hyland (eds), Information Systems and Activity Theory: Tools in context (pp. 19-38). Wollongong, NSW: University of Wollongong Press.

Hasan, H. (1999). Integrating IS and HCI using activity theory as a philosophical and theoretical basis. Australian Journal of Information Systems, 6(2), 44-55.

Hasan, H. (2003). Communities as activity systems and other such frameworks. In H. Hasan, I. Verenikina \& E. Gould (eds), Information Systems and Activity Theory. Volume. 3. Expanding the horizon (pp. 74-95). Wollongong, NSW: University of Wollongong Press.

Hasan, H., \& Gould, E. (2001). Support for sense making activity of managers. Decisions Support Systems, 31(1), 71-86.

Kaptelinin, V. (1996). Activity theory: implications for human-computer interaction. In B. Nardi (ed.), Context and Consciousness: Activity theory and human-computer interaction (pp. 103-16). Cambridge, Mass.: MIT Press.

Kaptelinin, V. (2002). Making use of social thinking: the challenge of bridging activity systems. In Y. Dittrich, C. Floyd \& R. Klischewski (eds), Social Thinking: Software practice (pp. 45-68). Cambridge, Mass.: MIT Press.

Korpela, M., Soriyan, H. A. \& Olufokunbi, K. C. (2000). Activity analysis as a method for information systems development: general introduction and experiments from Nigeria and Finland. Scandinavian Journal of Information Systems, 12(1), 191-210. 
Kuutti, K. (1991). Activity theory and its applications to information systems research and development. In H.-E. Nissen, H. K. Klein \& R. Hirscheim (eds), Information Systems Research: Contemporary approaches and emergent traditions (pp. 529-49). Amsterdam, Netherlands: Elsevier.

Kuutti, K. (1996). Activity theory as a potential framework for human-computer interaction research. In B. Nardi (ed.), Context and Consciousness: Activity theory and human-computer interaction (pp. 17-44). Cambridge, Mass.: MIT Press.

Kuutti, K., \& Virkkunen, J. (1995). Organisational memory and learning network organisation: the case of Finnish labour protection inspectors. Proceedings of the Twenty-Eighth Hawaii International Conference on System Sciences (HICSS), Wailea, HI, 4, 313-22.

Leontjev, A. N. (1981). Problems of the Development of the Mind. Moscow, Russia: Progress Publishers.

Nardi, B. (1996). Context and Consciousness: Activity theory and human-computer interaction. Cambridge, Mass.: MIT Press.

Nardi, B., \& O'Day, V. (1999). Information Ecologies: Using technology with heart. Cambridge, Mass.: MIT Press.

Pilemalm, S., \& Timpka, T. (2008). Third generation participatory design in health informatics - making user participation applicable to large-scale information system projects. Journal of Biomedical Informatics, 41(2), 32739.

Star, S. L. (1998). Working together: symbolic interactionism, activity theory and information systems. In Y. Engeström \& D. Middleton (eds), Cognition and Communication at Work (pp. 296-318). Cambridge, UK: Cambridge University Press.

Suratmethakul, W., \& Hasan, H. (2004). An activity theory analysis of a case of IT-driven organisational change. Proceedings of the IFIP TC8/WG8.3 International Conference: Decision Support in an Uncertain and Complex World.

Verenikina, I., \& Gould, E. (1998). Cultural-historical psychology and activity theory. In H. Hasan, E. Gould \& P. Hyland (eds), Information Systems and Activity Theory: Tools in context (pp. 1-18). Wollongong, NSW: Wollongong University Press.

Vygotsky, L. S. (1978). Mind in Society. Cambridge, Mass.: Harvard University Press. 